\title{
Espacio y Poder UNA MIRADA MATERIAL
}

\section{JORGE PROSPERO ROZE}

\section{INTRODUCCION}

La necesidad de profundizar nuestras reflexiones acerca del espacio, deviene de una no superada falencia que hemos tratado de resolver, sin éxito todos aquellos que operamos con ese aspecto de la realidad que se expresa como distancia, ámbitos, lugares, volúmenes, superficies, recorridos, etc.

Se trata del intento de establecer una coherencia entre nuestras elaboraciones teóricas y la práctica social concomitante, con la que conscientemente estamos comprometidos. Es decir, establecer nexos entre los espacios que proyectamos y las teorías sociales de las que somos tributarios.

En términos generales: la definición de los espacios, su calificación, las respuestas y las posibilidades de evaluarlos, se movían entre el subjetivismo más atroz, donde la existencia o no de teorías, marcos referenciales, análisis de la realidad, o como lo denomináramos, constituía una variable independiente respecto de los espacios que derivaban de la práctica, por ejemplo, de proyecto; o entre un pro- ductivismo tecnocrático y/o funcionalista donde la corrección y evaluación estaban dadas por la adaptabilidad extrema entre un programa y su respuesta.

Es decir, la crisis se manifestaba como una cesura entre teorías sociales y resultantes espaciales del diseño, imposible de llenar con técnicas o respuesta reflexiva alguna, donde las llamadas «teorías de la arquitectura», al moverse en las abstracciones idealistas vinculadas con «el» hombre abstracto y universal -de lo que haremos referencia-, oscurecían el panorama más que encaminar la práctica.

Ahora bien, a modo de vindicación, señalemos que hasta la década del ' 70 éste constituye un problema epistemológico que tiene varios anclajes; es decir, el espacio como «lo dado» en todas las teorías, era un inobservable en vinculación con diversas prácticas sociales.

Por un lado no había instrumentos teóricos suficientes para la construcción de respuestas; el pensamiento material en sus diversas versiones «marxistas» operaba, lejos de las formulaciones de sus fundadores, con un 
«hombre de la necesidad» devenido de los categorías vinculadas con visiones economicistas.

La ruptura epistemológica que haría posible una nueva visión material del espacio fueron las reflexiones acerca del poder que inauguran un conjunto de nuevos saberes acerca de lo social, particularmente el pensamiento de Michel Foucault y en geografía el grupo vinculado con la revista «Herodote».

A partir de esas reflexiones intentaremos aproximarnos a algunos operadores espaciales, vinculados en una primera etapa a la escala donde operamos los arquitectos y urbanistas.

\section{LO QUE TENEMOS}

La conformación de los espacios que el arquitecto -o cualquier otro agente vinculado con el diseño- estructura en su ejercicio profesional, constituye una práctica con escaso rigor explicativo, producto de una reflexión parcial e inacabada acerca de las relaciones entre sociedad y espacio.

Los intentos de sistematización en la práctica del diseño tienen como base tres elementos claves que operan en la parcialidad conceptual:

a) Las prácticas sociales consideradas a los efectos del proceso de diseño, son tomadas como resultado de un orden social donde los espacios son la mejor respuesta a ese orden; o son tomadas como sumatorias de hechos individuales, donde el orden social se construye en un supuesto consenso surgido de las diversas instituciones.

b) Los operadores metodológicos parcializan aspectos formales, perceptivos, tecnológicos, funcionales, geométricos o económicos y se constituyen como determinantes de una jerarquía de valores que serán definidores de las distintas corrientes donde se embanderan épocas, maestros, críticos y escuelas de arquitectura.

c) Se considera toda expresión espacial como continente, es decir neutral a todo tipo de contenido.

En este proceso, la teoría de la arquitectura, la supuesta práctica reflexiva que explica ese hecho social «cultural» recorre un camino inverso, elaborándose desde el producto (el edificio, la obra, el trazado de la ciudad) la razón humana de su existencia.

Obviamente, todas las teorías que asumen la arquitectura como un hecho «cultural» se asumen humanistas y parten del Hombre, donde de la mirada de ese concepto «hombre» surgirán con mayor o menor fetichismo, las determinantes de la práctica de construir sus espacios.

Aparece así el hombre de los «valores objetivos» que recorren toda la historia, con sus monumentos jerarquizados, determina el como de sus espacios. Esta escuela, tuvo singular influencia en nuestro medio a partir de uno de los fundadores de la facul- 
tad de arquitectura, el arquitecto Champion, continuada parcialmente por las cátedras de Teoría de la Arquitectura.

El hombre antropométrico, con las medidas de sus espacios posibles en la, expresiones del racionalismo donde el Modulor de Le Corbusier expresa su instancia matematizada.

El hombre historizado, con su herencia, con su deuda con el pasado, que en nuestras pampas se deslizarán al nacionalismo con sus casas blancas (1) y luego -en un nuevo historicismo- reciclarán galpones para loft y vestirán viviendas con ropajes posmo.

Ninguna pretensión teórica adquiere esta última corriente en la producción de conocimiento, ya que limitan sus trabajos a la recuperación de obras que califican previamente de monumentos.

Aparece en el ámbito del pensamiento crítico, el hombre de la clase o en una versión menos reflexiva del «pueblo» que disputa los recursos escasos en la construcción de sus espacios habitables, frente al despilfarro de las clases dominantes, que se plasman en funcionalismo o escapan a los determinantes de los espacios para primar el enfrentamiento en sus múltiples facetas.

En todos los casos nos encontramos que de la constelación de relaciones sociales que constituye el hombre («síntesis de múltiples determinaciones») se recorta una parcialidad de esas relaciones a los efectos de definir el sujeto, objeto de la reflexión.

\section{A MODO DE REFLEXION I}

Uno de los elementos más críticos en las historias de la cultura y en sus análisis es la caracterización de la obra como «consecuencia» de las determinaciones de cierta época.

Una suerte de reflejismo donde ciencia, arte, cultura resultan o del «espíritu» de la época o son la «expresion» de cierto tipo de poder establecido.

No escapa a esta visión un cierto materialismo que plantea, por ejemplo, «la ciudad como inscripción territorial de la lucha de clases» al decir de H. Lefevre (*).

Con ello, la obra es vaciada del presente en que hizo su aparición, desde el futuro donde tendrá el sentido de «conciencia». Tutankamon se convierte así en la momia de Tutankamon y la «momiedad» será el sentido de su existencia.

No. Cada objeto que en una determinada época se produce - y más aún si en el ámbito de la ciencia, el arte y la cultura-, son un lugar de lucha en el interior del cual se libran enfrentamientos en todos los ámbitos, pero especialmente en el de la lucha teórica.

Se disputan en él, múltiples aspectos de la lucha por el dominio teórico de su sociedad a través de la producción de saber, la producción de verdad, la legitimación de su existencia, donde su materialidad supone la derrota de todas las otras obras posibles en su espaciotiempo. Todos los esfuerzos por ejercer el dominio de ese lugar y el derecho a la existencia de aquellos que pudieron producirla frente a la nada de los que no lo hicieron o lo que tuvieron que hacerlo para construir la verdad del otro.

(*) Fourquet, F. Murard L. Les équipements du pouvoir. París. Recherches/13. 1978.

Así como en el ámbito de las relaciones sociales, Marx produjo una ruptura epistemológica que abrió paso a una nueva mirada de la realidad incorporando el ámbito de la producción a la reflexión dominada por las relaciones de mercado, es ahora la

(1) La instancia más intelectualizada de este movimiento arquitectónico se expresaría en la obra de Caveri, tanto sus textos de crítica cuyos destinatarios fueron las corrientes marxistas, como sus casas blancas, la iglesia de Fátima, etc. 
incorporación de un nuevo ámbito de análisis: una concepción relacional del poder, nos permite una apertura a nuevas reflexiones que aparecen con una significativa capacidad heurística para la problemática del espacio.

\section{UN CAMINO}

Ni el hombre «humanizado» con sus espacios aparentemente producto de su voluntad individual o como «hechos sociales», ni el enfrentamiento abstracto. La tarea es rastrear nuevos caminos que nos permitan vincular la práctica histórica y social de un determinado modo de producción -el capitalismo en todas sus determinaciones- con las configuraciones necesarias de sus espacios para la existencia misma de nuestras formaciones sociales-históricas.

Una serie de nuevas perspectivas abiertas por las corrientes críticas del pensamiento en diversos ámbitos disciplinarios, que replantean los estatutos epistemológicos en filosofía, psicoanálisis, antropología, geografía y ciencias políticas, nos obliga a repensar nuestro ámbito teórico a partir de sus reflexiones.

(2) Hay una notable distancia entre el hacer y el saber como se hace. Constituyen dos procesos diferentes. Este descubrimiento crucial fue formulado por Marx en relación con la historia y operativizado por Piaget, quien a través de sus experiencias da cuenta de los mecanismos implicados en la acción y la conciencia de la acción. Cfr. Piaget, Jean; La toma de conciencia; [1974]; Ed Morata; Madrid; 1981.

(3) Un trabajo importante en este sentido es «Espacio y Poder» de Paul Claval (ver Bibliografía), cuyo punto de partida son los analisis de Max Weber acerca de las diferentes formas de dominación.
No es nuestra pretensión construir una teoría de la arquitectura o del espacio.

Es, tal vez, saldar una deuda con el pensamiento material acerca de la determinación de los espacios, donde el proceso de diseño o configuración de los mismos no sea producto de una práctica artesanal, solo explicable por sí, donde «hacemos, pero no sabemos como» (2) o se pida prestadas sus bases a formalizaciones abstractas que han transformado sus prácticas metodológicas en bases epistemológicas en sus disciplinas.

Es, solamente, un intento de mostrar un camino posible.

A los efectos del proceso de análisis, hemos elegido un estilo (que tomamos prestado de Foucault, así como muchas reflexiones) que nos permita construir una reflexión entre «una imagen y el juego íntimo de sus motivaciones», para luego formular los elementos que definen determinados dispositivos espaciales para una estrategia, cuyo objetivo final, subyace en la determinación de condiciones necesarias para la existencia del orden actual de nuestras sociedades.

No hacemos gran diferencia entre aspectos arquitectónicos y/o urbanísticos en los ejemplos, cada caso nos remonta a la génesis estructural de fenómenos que tendrán correlatos espaciales.

\section{DEL PODER AL ESPACIO (3)}

Un primer recorrido posible en el juego de la reflexión: partir de las 
premisas del poder y observar las consecuencias en los espacios.

¿Cuáles son los elementos que en el campo de la arquitectura o del urbanismo u otro tipo de espacialidad se relacionan de alguna manera con aspectos vinculados con el poder?

Una primera forma posible de acercarnos al problema, es observar la arquitectura o los espacios que generaron los poderosos y reflexionar sus relaciones. No es un esfuerzo que suponga mucha búsqueda documental ya que toda la historia de la arquitectura es la historia de esos monumentos.

La acumulación dominante en este campo es la exaltación del poder de la divinidad. Una pregunta en cuya respuesta aparece una bifurcación en las concepciones teóricas es:

¿Por qué el poder terreno exalta dominantemente el poder divino? (4)

Porque toda forma de poder estamental se legitimaba en la decisión divina de que determinado individuo fuera monarca, rey, noble, príncipe o como se autodenominaran.

En ese sentido, el mantenimiento de una burocracia sacerdotal que orientara los problemas de difícil o imposible solución a un decididor supremo fue funcional en todas las épocas y a todo tipo de dominación.

No obstante a los efectos de un análisis más acabado, debiéramos precisar el carácter de poder universal de la iglesia en la edad media, y sustento de un cierto tipo de civilización, a los efectos de explicar la universalidad de sus monumentos.

\section{A MODO DE REFLEXION II}

A los efectos del uso del espacio con fines económicos-políticos, a fines del siglo XIX se instaurarían en su producción, por un lado, dispositivos disciplinarios y por el otro su organización funcional.

Expresión plástica de una sociedad que se ajusta a diversos dispositivos creados por el hombre como si fueran leyes naturales y estuvieran fuera del control de sus creadores.

La ficción de que «la ley legitima la costumbre», ocultando que es en realidad la legitimación de la dominación o la imposición de ciertas costumbres por parte de una fracción dominante a otra subordinada, a los efectos de atar esa subordinación (premisas morales, cumplimiento de horarios, etc.) hasta en la propia constitución física del individuo.

Así tambiên, que los espacios tomen forma según una lógica productiva, forma necesaria a la tarea que en ellos se realizan aparece como lo «natural», como propio de una naturaleza de lo que los hombres no hacen sino expresar.

Los espacios así creados pasan a ser «los mejores posibles»; «los únicos posibles». Cuando «lo real es racional» y «lo racional es real» la construcción de racionalidad aparece como el legitimador de lo verdadero y esa positividad va a desplazar las respuestas políticas a los problemas de la sociedad al ámbito de la razón instaurado en ciencia y producción industrial -donde el todo, para ser natural debe entrar en los cánones fundados en esas premisas-, desde la corporalidad de los individuos, hasta los espacios ahora funcionales.

Esta disciplinariedad fundada en la eficiencia del trabajo, que expresa su mayor potencia en el taylorismo y el fordismo constituirá la indiscutible verdad del funcionalismo que funciona como sustrato, aun en las concepciones más críticas de la producción arquitectónica, imponiéndose en última instancia.

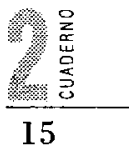

¿Cuál es el elemento que a través de la monumentalidad produce relaciones de asimetría entre situaciones estamentales?

(4) La remisión a una teoría que ponga su acento en la objetividad esencial e histórica de los valores establece una respuesta de fuerte coherencia, a condición de suponer una esencia inmutable en el hombre. El arq. Champion remitía a una escala de valores en cuya cúspide se hallaba el valor religioso y eso daba total coherencia al fenómeno. 


\section{A MODO DE REFLEXION III}

Cuando se habla de poder, tropezamos con una tendencia implícita de cosificación en dos aspectos fundamentales: 1. el poder como aparato, institución centro de irrạdiación de decisiones, 2. la propiedad, posesión o uso de alguna cosa, arma, organización, etc.

En ambos casos, estos análisis tienden a hacer determinante algún tipo de propiedad vinculada con la cosa, y remitirnos al campo de las leyes naturales.

Un nuevo orden de pensamiento que se funda en los trabajos de Niesche reorienta las reflexiones alrededor del poder y plantea un conjunto de nuevas perspectivas, enviando el poder al núcleo mismo de las relaciones entre los hombres. Se piensa en una microfísica del poder.

El poder nace de abajo, esta inscrito en todas las relaçiones entre los individuos. Es producto de esas relaciones. No tiene titulares. El poder se ejerce o se cede para que alguien lo ejerza. No hay poder sin su ejercicio. Es una trama compleja en la que todos estamos sujetos y constituimos puntos de conexión.

El poder es constitutivo del sujeto. El individuo es un efecto del poder. El poder no es solo violencia y dominạción, no solo reprime sino también produce. Sus redes combinan placer y saber a la par que acciones que normalizan, discriminando la razón misma de lo social entre lo normal y patologico, lo bueno y lo malo, lo «natural» y lo contranatural, etc., no en un juego aleatorio y perverso, sino se conforma siguiendo líneas estratégicas que recorren largos períodos de la historia.

\section{El espectáculo}

La puesta en escena de la grandeza de la soberanía en juegos de impresión básicamente visual -aunque apelaren a otros sentidos- marcaban la distancia entre el plebeyo o el campesino atado a su comunidad y el poder del que era tributario.

Esta grandeza que expresaban las piedras de las iglesias y palacios, se

(5) Cfr. Canetti, E. Masa y poder. Barcelona. Muchnik Editores. 1981. transmitía también al cuerpo del soberano que representaban. Los fastos del espectáculo permanente de los estamentos dominantes, implicaban en esa relación de dominio, juegos de miradas que los potenciaban:

a. La situación de espectador de todo aquel que debe sufrir ese tipo de dominio

b. Implicada con ello, la conciencia de que hay otras situaciones del espectáculo inaccesibles, secretas, (5) donde además se deciden los destinos de todos, a través de mecanismo solo existentes en la imaginación de sus destinatarios. (Impuestos, servidumbres, castigos).

c. La luz que expande el espectáculo de la soberanía, tiene su correlato en la existencia de las oscuridades infinitas que supone sustraerse a sus poderes (cárceles, mazmorras).

d. La sensación del peso, volumen, fuerza, permanencia que implicaban los monumentos, implican también en la relación de dominación, (las habitaciones con diferentes niveles de accesibilidad, según jerarquías, la inviolabilidad de las mazmorras, la inaccesibilidad de las torres, etc.).

Asimetría fuertemente construida entre el nexo con la divinidad que expresa el noble, por un lado, y el individuo sujeto a su suerte, por el otro, donde la vestimenta, los movimientos, los rituales, los secretos, construyen señales inequívocas de la fuerza que ha construido la dominación. 
Este dispositivo alcanzará su máxima expresión en la corte, conservada en nuestra época en el ámbito eclesiástico y en la páginas de las revistas del «gran mundo»

\section{La guerra}

La otra expresión del poder con un singular correlato espacial es la práctica de la guerra. (6)

El intercambio de hostilidades entre diferentes grupos, etnias, clases, situaciones, etc., expresó un cierto tipo de relación con correlato espacial que recorre toda la historia, y es un tanto menos vista en la historia de la arquitectura.

El elemento delimitador del espacio controlado es la muralla.

A las incursiones de los hombres de a caballo, salteadores de caminos, bandidos, invasores, etc. se opuso la muralla, la ciudad cerrada, la ciudad amurallada. (7)

El freno al extranjero, definiendo sus límites en el adentro como espacio de los que forman la comunidad, es a la par, y singularmente también delimitador de un espacio factible de ser controlado por algún tipo de poder o de poderoso

Doble lectura del espacio amurallado.

* La muralla determina el límite para los de afuera Las incursiones del enemigo tropiezan con un área donde la dificultad de acceso la hacen extraña, ajena. No le pertenece; pertenece al otro; a otro po- der, a otro poderoso. El adentro de la muralla encuentra su razón en la defensa del extrajero.

* La muralla determina un límite para los de adentro. Es la expresión del área de control de algún poderoso. Se está adentro, se pertenece, en la medida que se es tributario de alguna autoridad.

Primer gran dispositivo de enciero.

Otro de los dispositivos espaciales vinculados con el poder debido a la guerra, que influyó fuertemente en el trazado de ciudades - en principio a lo largo de la colonización romanacon influencia a lo largo de la historia es:

\section{EL CAMPAMENTO MILITAR Los espacios de la mirada}

La vigilancia, el control ejercido a través de la mirada, es la más antigua expresión globalizante del poder de un cierto aparato institucional de dominio, tiene su más antigua expresión en la revista de las tropas; los mirado-

(6) Contra todo prejuicio «humanista» importa señalar el carácter determinante de nuevas relaciones sociales, procesos de conocimiento, avances tecnológicos y todo aquello que puede denominarse «progreso general de la humanidad», de la práctica humana de la guerra. Desde distintos puntos de vista, Cfr. las reflexiones de Marx (1857-58) y Weber (1923).

(7) Una de las reflexiones más profundas acerca de la relación entre el hombre de a caballo y la ciudad, constituye el ensayo de Jorge Luis Borges Historias de Jinetes, publicado en su libro Evaristo Carriego en 1930. 
res de castillos y palacios; los minaretes y púlpitos de los rezadores, altares y estrados de los maestros.

Adquiere inclusive distribución espacial (en un largo proceso histórico que se inicia en los castros romanos) en la arquitectura de los campamentos militares.

En un documento que rescata Foucault -Reglement pour l'infanterie Prussienne- (8) se señala:

«En la plaza de armas, se tiran cinco líneas, la primera de 16 pies de la segunda; las otras a 8 pies de las defensas. Las defensas están a 10 pies de las tiendas de campaña de los oficiales inferiores, precisamente frente a la primera pieza emplazada. Una calle de compañía tiene 51 pies de anchura...

Todas las tiendas de campaña están a dos pies unas de otras.

La de los subalternos están frente a los pasadizos de sus compañías. La puerta mira hacia las mismas compañ́as».

Este primitivo diagrama tiene como base la visibilidad general donde desde ciertos puntos jerarquizados, las categorías superiores pueden controlar con una mirada las categorías subalternas en un orden que comienza en las tiendas de los oficiales superiores y termina en los soldados.

Este esquema siempre perfectible

(8) Foucault. [1975] p. 199 de establecimiento del control a través del cruce de miradas jerarquizadas, fue base del diseño urbanístico de ciudades obreras, de los hospitales de pabellones; de asilos y todo tipo de casa de educación.

El principio subyacente:

Encaje espacial de vigilancias jerarquizadas.

Principio del empotramiento.

La arquitectura para ser vista -palacios, iglesias- o para vigilar el espacio exterior -geometría de las fortalezasque va a caracterizar la edad media hasta la aparición de las formas que configurarían el capitalismo, va a dejar cada vez mayor lugar a la arquitectura para vigilar a los que están adentro; control de multitudes, visibilidad del conjunto y de los individuos.

Dos tipos de miradas determinan mecanismos de poder a través del ordenamiento de espacios y dispositivos arquitectónicos: El espectáculo y el poder que controla con la mirada.

En principio, las ciudades cerradas recorren todo lo largo de la historia. Un espacio de adentro amurallado, protegido del peligro que está afuera de los límites. En ese interior viven en forma permanente los estamentos privilegiados y es refugio en caso de invasiones.

Es la arquitectura del castillo, la fortaleza, la abadía medieval cuyo elemento típico, aparte del muro y su localización es la torre. 
La torre es la mirada del poder de adentro sobre el territorio controlado. Arquitectura para ver las multitudes enemigas, es también, arquitectura para ser vista como fuente de poder bélico.

El poder armado que se eleva sobre el terreno e impone su presencia. Arquitectura que transmite otro mensaje, pero el dispositivo básico del juego de la mirada indiscriminada de y sobre la multitud es el mismo de templos y palacios. La torre también fue lugar de encierro de prisioneros privilegiados.

El poder en este dispositivo expresa la desigualdad, la distancia social, la asimetría, la debilidad de los sometidos frente a la fortaleza del poderoso.

Se sustenta en la propiedad del medio de producción por excelencia en esa época: la tierra, en manos del rey por decisión divina. Se es poderoso porque se puede controlar un espacio de territorio de la hostilidad de sus vecinos, recaudar impuestos y defender a sus tributarios.

Muralla, castillo y torre, constituyen dispositivos espaciales y constructivos cuyo alcance se verá limitado al modo productivo y político que los sustentaba. Nuevos dispositivos deberán aparecer frente a nuevas situaciones. En ese marco:

\section{LA CIUDAD ABIERTA}

Complejos procesos de división social y territorial del trabajo determinaron la aparición de las ciudades sin murallas. Aparece un nuevo sujeto en la historia: el pueblo. (9) Nuevas formas de trabajo; nuevas sociedades; nuevas relaciones sociales.

Las sociedades de nobles y campesinos se diversificarían en nuevas clases, grupos, asociaciones, corporaciones que redeterminarían y potenciarían los niveles de sociabilidad. Comerciantes, artesanos, y una plebe no ligada al trabajo de la tierra constituirían las ciudades.

En sus comienzos, los dispositivos de poder con que las nuevas clases manifestarían nuevas y necesarias formas de asimetría y sujeción fueron similares a las del período que fenecía, no obstante, así como «el aire de la ciudad hace hombres libres», la ciudad gestaba nuevas formas de limitación de la libertad que se conquistaba con la ruptura del sistema feudal.

La ciudad es el desafío constante para el poder fundado en la autoridad, la opresión, y el encierro del «pequeño mundo» de la aldea.

El control de las conductas fundado en la mirada del vecino, en la existencia de la identidad indisociada de una familia, un lugar, una actividad, entra en crisis con la aparición de un nuevo fenómeno: las multitudes urbanas, y la construcción del individuo. (10)

(9) Max Weber situaría el fenómeno inicialmente en ltalia con la aparición del popolo. La nueva forma de dominación incluiría ahora la existencia de instituciones regidas por el derecho. Cfr. el capítulo «La dominación no legítima (tipología de las ciudades)» en Weber, M. (1918)

(10) «...se requiere un gran esfuerzo de autodistanciamiento, para comprender que existen sociedades y existieron niveles de evolución de la propia sociedad en los que 
No hay ya murallas que controlen el movimiento. De la ciudad se entra y se sale, se circula como las mercancías del floreciente comercio.

El nuevo agrupamiento de personas, las nuevas formas de socialización, las nuevas formas de explotación, eran a la par, nuevas y más poderosas fuentes de conflictos. La escasa distancia entre unos y otros, problemas comunes y localizados, clases antagónicas que convivían un espacio común, fueron fuentes de revueltas y nuevos enfrentamientos.

Así, los dispositivos de control debieron ser recreados, la autoridad, en su crisis, elabora utopías y realidades del poder.

Dos imágenes provenientes de una situación extrema son las dominantes del sueño de los poderosos ambas nos llegan de la historia en leyendas y reglamentos. Inscripta en la memoria colectiva como crisis sin solución, aparecen las utopías de la ciudad apestada.

\section{LA CIUDAD APESTADA Los espacios del orden}

¿Cúales son las imágenes de la ciudad apestada?

no había términos como «individual» y «social» con el significado que poseen ahora, y para preguntarse qué tipo de desarrollo social condujo a que se adoptara y mantuviera el empleo de estos términos» [p. 180] Elías. N. 1990.

(11) Apelo a una imagen: Quien ha visto la película « $\phi$ sferatus» de W. Herzog puede recordar la mas acabada imagen del fenómeno donde a la confusión de los cuerpos se mezclan las ratas en una fiesta final.

(12) Foucault. [1975] p. 199 y (1990), conferencia 7 Historia de la medicalización, p. 137.
La primera y más universal: en medio del caos y la desesperación la gente asume su próximo destino inapelable y vive lo que le queda de vida a través de la fiesta.

Frente a la inexistencia del mañana las leyes y jerarquías se igualan. Se trata de vivir los últimos momentos. Gozar lo que nunca se gozó, porque el castigo no tiene lógica. Como todo es confuso. Los cuerpos en la fiesta se amontonan y mezclan con la confusión devenida de la ruptura de todo orden que los hombres impusieron y la divinidad en este momento sanciona. (11)

La fiesta es la instancia extrema de la ruptura del orden. Pesadilla de unos, sueño de otros, la desaparición de las distancias sociales determina un espacio homogéneo sin barreras, sin límites, sin jerarquías, sin prohibiciones.

Las bacanales de la muerte nos señalan una dimensión de una ciudad donde somos todos igualados por un juez inapelable, la muerte, y una resultante espacial sólo posible en los límite de la existencia misma.

Utopía de los desposeídos en busca de revancha en la tierra.

La otra, menos observable, menos difundida, socialmente inobservable: el imperativo del orden.

$\mathrm{Al}$ analizar reglamentos militares acerca de las medidas a aplicar por las autoridades militares en las ciudades afectadas por la peste, Foucault reproduce un caso paradigmático, (12) del que sintetizamos los aspectos salientes referidos a las determinaciones espaciales: 
a. División del espacio. La ciudad se divide en zonas donde se establecen autoridades por áreas y autoridades por calles.

b. Reclusión. Cierre de la ciudad y el área circundante. No se puede salir ni entrar bajo pena de muerte.

Guardias en las puertas de la ciudad. Centinelas en el extremo de cada calle.

Cierre de todas las casas por parte de las autoridades.

Prohibición de salir y circular bajo pena de muerte hasta el fin de la cuarentena

c. Fijación. La circulación se reduce a las autoridades; los soldados dispuestos para el orden y los que operan con cadáveres (gente inferior, «de otra especie» que no importa a la ciudad).

Los animales errantes son sacrificados.

Las provisiones de cada uno han sido previstas antes del cierre. Los bienes perecederos -carne y panson trasladados a cada vivienda por canales al efecto para que no haya ningún contacto con los proveedores.

d. Control. Todos los días los responsables controlan los informes de secciones.

Los responsables por calles averiguan si en cada vivienda están quienes deben estar, tomando asistencia diaria, obligando a asomarse a las ventanas, para verificar el estado de cada uno (vivo, apestado o muerto).

Mentir está penado con la muerte. El objetivo es saber si no se está ocultando muertos o enfermos.

Registro riguroso por cadena de informes entre autoridades donde cada uno tiene las listas de habitantes.

Con la inspección diaria se tiene el registro de las novedades, hechos, quejas, problemas.

e. Higiene y Salud. El cuerpo médico ha sido organizado, jerarquizado, estableciéndose sistemas de control en que participan enfermeros, boticarios y confesores.

Se purifican cada una de las casas, haciendo salir a todos sus habitantes, levantando o suspendiendo los muebles y quemando perfume en cada una de las habitaciones, selladas al efecto, por un cuerpo especial. Se registra públicamente la entrada y salida de cuerpos y cosas para evitar pérdidas.

Cuatro horas después la casa vuelve a ser ocupada.

¿Qué supone la presentación de este reglamento, (que posiblemente nunca se cumplió), pero que se puede encontrar, en diferentes versiones y circunstancias a lo largo de toda esa época?

Es una idealidad en el ejercicio del poder sobre la ciudad.

Si pensamos la ciudad como el espacio de la movilidad, la mezcla, la ruptura de las rígidas estamentaciones de la edad media; el espacio de la ciudad iguala, a través del mercado a locales y extranjeros.

«La ciudad hace hombres libres»; es decir, hombres sin controles ni 
obligaciones con la autoridad territorial o la iglesia.

La utopía, el sueño de la ciudad controlada, en este caso de los poderosos, se realizaría a través de la situación extrema de la peste.

¿Cuáles son sus características espaciales?

¿Cuáles son los dispositivos espaciales de una ciudad bajo control?

1. Espacio recortado, inmóvil, petrificado.

Cada uno en su lugar, o la muerte (el castigo o el contagio)

2. La inspección funciona sin cesar.

La mirada en movimiento.

(Revista constante de vivos y muertos)

3. Registro de lo patológico, permanente y centralizado.

La relación de cada uno con la enfermedad o la muerte se debe vincular necesariamente con la jerarquía del poder. Cada cuerpo está constantemente situado, registrado, controlado y categorizado entre sanos, enfermos o muertos.

4. En tanto la peste no respeta jerarquías, mezcla, desordena, desarticula, el poder aplica el análisis, recomponiendo un reticulado disciplinario. Cada quién en su lugar.

5. El poder puesto en crisis debe reconstituirse a través de un reglamento. Reglamento que no refiere ya a grandes líneas de acción, sino a penetrar en cada uno de los movimientos a los efectos de hacer funcionar, con jerarquía renovada, el funcionamiento del poder. Reglamento que regula espacio y tiempo, localización y movimiento. Reglamento del orden de hombres y cosas.

En síntesis:

El espacio cerrado, dividido, estatizado y controlado.

Entre nosotros, esta utopía absurda mantiene lineamientos políticos de la ciudad «ordenada» de muchos planificadores urbanos.

\section{EL INDIVIDUO APESTADO. EL LEPROSO La exclusión y el Gran Encierro}

Una nueva imagen en el juego de la reflexión acerca de los espacios y del poder: El leproso, el individuo enfermo que contagia.

¿Qué nos puede sugerir, en un análisis de la configuración de los espacios, la imagen del individuo portador de la enfermedad?

En principio, nada vinculado con su aspecto, no obstante, esta figura típica de la edad media, nos habla de una conducta de la sociedad que se codifica y transforma ámbitos espaciales.

Es la imagen inversa de la ciudad apestada. El apestado excluido. Allá se trataba de controlar integrando. Aquí la sociedad sana, excluye los indeseables.

El leproso que recorre los caminos ocultando sus llagas y con una cam- 
panilla para anunciar su carácter de intocable, de excluido con quien no hay que tomar contacto. (13)

Es a la vez, el modelo del Gran Encierro

No se trata -decíamos- de la situación coyuntural de la ciudad apestada que lucha colectivamente por curarse (aunque en su seno las jerarquías determinan el derecho a la vida).

Se trata de la comunidad pura que excluye al individuo extraño, al enfermo, al impuro. Puros e impuros; Sanos y enfermos; Buenos y malos; Normales y anormales, y así una dicotomía infinita que determina los comportamientos.

Se trata del exilio-clausura que significa que la sociedad separa a aquellos que la pueden contaminar, al indeseable.

¿Qué pasa cuando la sociedad se masifica - no hablo todavía de «sociedad de masas»-y se pierde la condición de establecer marcas; puntualizar la diferencia, evidenciar la exclusión?

Ese dispositivo de exclusión, sufrirá a lo largo de los siglos una inversión que tendrá importantes correlatos espaciales:

El siglo XIX planteará la exclusión a través de la creación de reticulados disciplinarios.

El espacio de adentro (social) se transformará en el afuera, en un doble juego de encierro.

Los excluidos (enfermos, locos, mendigos, violentos $y / o$ vagabundos) no pueden ser masivamente apartados, por lo que la sociedad transformará la exclusión en ámbitos de encierro particularizado, donde opere el control, el análisis y supuestamente, la cura o su transformación en individuos útiles.

\section{Aparecen así:}

El asilo para los viejos.

El Psiquiátrico; depósito de locos, después institución de análisis.

La penitenciaría, El correccional: violentos y vagabundos

Los establecimientos de educación vigilados.

Fue preciso para ello el desarrollo de una larga serie de procesos, en los que estos dispositivos de encierro, juegan con su espacialidad, un papel fundamental:

Inicialmente un doble juego: establecer los parámetros normal/anormal; sano/enfermo y construir los aparatos de saber que los perfeccione.

Es necesario para ello la determinación del secuestro de los ciudadanos $\sin$ violar las normas legales que los protegen. (14)

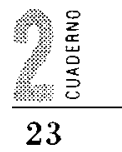

(13) Nuevamente una imagen cinematográfica. De Mario Monicelli: "Brancaleone en las Cruzadas", donde la «doncella» para protegerse y poder realizar su peregrinación, sola, se viste con ropa de leproso.

(14) Estamos refiriendo a épocas en que se está construyendo «la sociedad de los individuos» con la aparición de todos sus derechos. Se trata de determinar mecanismos para sacarlos de la sociedad; encerrarlos, secuestrarlos, sin violar los derechos mas elementales a la libertad, a la circulación, a la vida. 
¿Fue este un proceso realizado con total conciencia y con objetivos claros, o fue el cruce de un conjunto de circunstancias que se fueron configurando en los aparatos que conocemos?

Lo que se denomina «gran encieпro», implicaba precisamente, el encierro indiscriminado de todos aquellos individuos que por una razón u otra la sociedad excluía: locos, prostitutas, rebeldes, enfermos, inadaptados, ladrones, criminales, etc.

Un momento importante de ese encierro, es cuando, quienes los tienen a cargo -guardianes, cuidadores, etc.- pueden determinar conductas diferenciales entre ellos (aquellos que responden a determinados llamados, los que colaboran, los que se aislan, etc., etc.) y empiezan a brindar tratamiento diferenciado.

Ese tratamiento diferenciado, con el tiempo se convertirá en encierro diferenciado o diferentes ámbitos de encierro, en estudio de cada uno de estos tipos, en programas de incorporación a la comunidad; es decir, se convertirán en lo que conocemos como instituciones.

Es así, que legitimados por el juego de cientificidades crecientes aparecen las instituciones de secuestro.

Todos los valores de nuestra vida y por consiguiente nuestra conducta, están regidos por las imágenes de estas instituciones de secuestro, que inclusive tienen especificiedades arquitectónicas para hacer deter- minado y definido el adentro y el afuera. La prisión y el manicomio son los aparatos extremos, pero juegan un fuerte papel los asilos, hospitales o institutos cerrados. Finalmente, aun sin percibirlo, convivimos con los encierros cotidianos influidos por los aparatos de secuestro como las fábricas y las escuelas.

¿Cuáles son las diferencias entre reclusión y secuestro?

Son las diferencias entre dos sociedades y básicamente dos concepciones del poder. Relaciones de oposición.

1. La reclusión del siglo XVIII está esencialmente dirigida a excluir a los marginales y reforzar su marginalidad.

2. El secuestro del siglo XIX tuvo por finalidad la inclusión y normalización.

La primera excluye a los individuos del círculo social, mientras que la otra tiene por función ligar los individuos a los aparatos de producción a partir de la formación y corrección de los aparatos productores. Se trata de una inclusión por exclusión.

Las instituciones de encierro: fábrica, escuela, hospital, psiquiátrico, prisión, no tienen por finalidad excluir, sino por el contrario fijar a los individuos. Se fija al obrero a los aparatos de producción, a los niños al aparato de transmisión de saber, el hospital 
los fija. a un aparato de cura, la prisión a un aparato de corrección y normalización, etc.

Se garantiza de este modo la ejecución de las tareas, la producción por los productores en forma determinada, la cura bajo ciertas condiciones, etc.

Son instituciones que se encargan de todo lo relativo a la dimensión temporal de la vida de los individuos.

Una diferencia entre las sociedades primitivas, incluido el feudalismo, con el sistema capitalista, es que en esos sistemas de producción anteriores, el individuo pertenece a un grupo porque está fijado a una cierta localización territorial, incluido en un ámbito geograficamente determinado. El sistema capitalista rompe este esquema. Ahora el hombre, liberado de sus lazos comunales, territoriales, feudales; «libre» importa en cuanto al uso de su tiempo. (15)

Se hizo imprescindible controlar el tiempo, en la medida que el trabajo no se expresaba ya en productos, sino que se convirtió en una mercancía que se pagaba como salario, en fuṇción del tiempo de producción.

De allí la necesidad de técnicas de explotación del tiempo de los individuos, a través de lo que conoceremos como instituciones de encierro.

Esas instituciones, con un discurso que las hace aparecer encaminadas a brindar protección y seguridad, establecen mecanismos por el que todo el tiempo de la existencia es puesto a disposición de un mercado de trabajo y las exigencias del sistema de producción.

\section{Funciones de las instituciones de secuestro}

La primera función es el uso de la totalidad del tiempo del individuo, organizándolo a los efectos de su mayor rendimiento.

La segunda no consiste ya en controlar el tiempo de los individuos, sino, simplemente, sus cuerpos. Todo esto se relaciona con los problemas de la moralidad, higiene y control sexual.

Nunca nos preguntamos por qué en la escuela donde se enseña a leer y escribir, se obliga a las personas a lavarse.

Son imperativos del control de la totalidad de la existencia de los individuos. El cuerpo debe ser formado, reformado, corregido, cualificado, sumar aptitudes, calificarse para el trabajo.

Transformase en cuerpo productor, sustento de la fuerza de trabajo.

Así, la transformación del tiempo de los individuos en tiempo de trabajo se corresponde a la transformación del cuerpo en fuerza de trabajo. Ambos procesos son instrumentados por los aparatos institucionales.

La tercera razón de las instituciones de secuestro consiste en la creación de un nuevo tipo de poder: poder polimorfo, polivalente. Poder que funcionará en un contexto jurídi$c o$, pero que se constituirá al lado, di-

(15) Cfr. Marx, C. y Engels, F. [1858] 
ferente, casi contra la soberanía, no importa si de un rey o de un parlamento democrático. Es un poder particular donde los individuos son alcanzados y apartados de sus derechos determinados por su condición de ciudadanos

Por lo menos hay cuatro tipos de formas de poder que el encierro define e identifica, delimita consolida e inscribe socialmente:

a. Un poder económico individualizado. Las instituciones por un lado definen situaciones particulares de economía en su funcionamiento (aranceles, pago de tratamientos, sueldos, etc.), y por otro, el cuerpo de aquellos que involucra son cuerpos puestos a disposición de la producción particular de la institución (saber, trabajo, productos, información), etc.

b. Un poder político interno y definido. ¿Nos hemos preguntado por qué los que las dirigen se arrogan el derecho de dar órdenes, establecer reglamentos, tomar medidas, expulsar a algunos, aceptar a otros, etc.? ¿Nos hemos preguntado por qué cuando nos incorporamos a alguna institución en términos de «beneficiarios» perdemos un conjunto de derechos de autodeterminación y nos sometemos a la voluntad de un igual que puede de-

(16) Este elemento propio de la arquitectura, de singular significación, como veremos, permaneció en el más oscuro silencio del discurso polifacético de los historiadores de la cultura, de los teóricos de la arquitectura, de los hombres de saber. Lo descubre Michel Foucault a casi 200 años de su nominarse «director», "maestro», «médico», «encargado» ... etc.?

c. Un poder jurídico, donde las autoridades de la institución se arrogan el derecho de castigar o recompensar. Igualmente, ¿Cómo se hizo posible que en el interior de las instituciones nos sometamos a un aparato judicial propio de cada una de ellas, y debamos acatar sus juicios, que en ciertas circunstancias pueden afectar la casi totalidad de nuestra existencia? ¿Qué justificación existe para que se castigue corporalmente a los presos, a los soldados, y hasta hace muy poco a los niños en las escuelas? ¿Por qué, en esta sociedad democrática, donde todos somos ciudadanos, las instituciones pueden discriminar quienes pueden entrar, permanecer o ser expulsados?

d. Finalmente hay un poder epistemológico. Estas instituciones, en la práctica de todos los días de observar, actuar, analizar a todos aquellos sometidos a sus poderes, producen saber. Se constituyen en lugares del saber por excelencia.

Este poder adquirirá diversas expresiones espaciales: tipologías de escuelas, de hospitales, de cárceles. Cambiarán con el tiempo y con diversos sistemas reglamentarios.

No obstante, existió un diseño arquitectónico que, recorrería la historia imponiendo su presencia, pero en un significativo silencio por parte de los historiadores de la cultura.(16)

Se trata del Panóptico. 


\section{PANOPTICO}

A mediados del siglo XVIII (1791) un reformador inglés llamado Jeremías Bentham lanzó una propuesta arquitectónica al gobierno inglés, que posteriormente sería presentada al gobierno revolucionario francés y que habría de tener un singular efecto sobre la concepción de la arquitectura.

A pesar del impacto producido en su época, nunca fue registrado por la historia de la arquitectura, aunque con variaciones su influencia se extendería a lo largo del siglo XIX e indirectamente a nuestra época.

Se trataba en principio, de una propuesta de unidad carcelaria con las siguientes características:

«... un edificio circular, o por mejor decir, dos edificios encajados uno en otro. Los cuartos de los presos formarian el edificio de la circunferencia con seis altos, y podemos figurarnos estos cuartos como unas celdillas abiertas por la parte posterior, porque una reja de hierro bastante ancha los expone enteramente a la vista. Una galería en cada alto sirve para la comunicación, y cada celdilla tiene una puerta que se abre hacia esta galería.

Una torre ocupa el centro, y esta es la habitación de los inspectores; pero la torre no está dividida mas que en tres altos, porque están dispuestos de modo que cada uno domina de lleno sobre dos líneas de celdillas. La torre de inspección está también ro- deada de una galería cubierta con una celosía transparente que permite a el inspector registrar todas las celdillas sin que lo vean, de manera que con una mirada ve la tercera parte de sus presos, y moviéndose en un pequeño espacio puede verlos a todos en un minuto, pero aunque esté ausente, la opinión de su presencia es tan eficaz como su presencia misma.

...Entre la torre y las celdillas debe haber un espacio vacio, o un pozo circular, que quita a los presos todo medio de intentar algo contra los inspectores.

El todo de este edificio es como una colmena, cuyas celdillas todas pueden verse desde un punto central. Invisible el inspector reina como un espíritu; pero en caso de necesidad puede este espiritu dar inmediatamente la prueba de su presencia real.

Esta casa de penitencia podría llamarse Panoptico para expresar con una sola palabra su utilidad esencial, que es la facultad de ver con una mirada todo cuanto se hace en ella». (17)

¿Cuál es el programa en que Bentham funda su propuesta?

«Si se hallara un medio de hacerse dueño de todo lo que puede suceder a un cierto número de hombres, de disponer de todo lo que les rodea, de

enunciación, precisamente, como lo señalamos al comienzo, porque pudo producir una ruptura epistemologica en el campo del saber al salir del encierro de las «esencias del Hombre» del Humanismo clásico.

(17) Bentham. J. El Panóptico [1822] (1979. p. 36-37) 


\section{PANOPTICO DE BENTHAM}
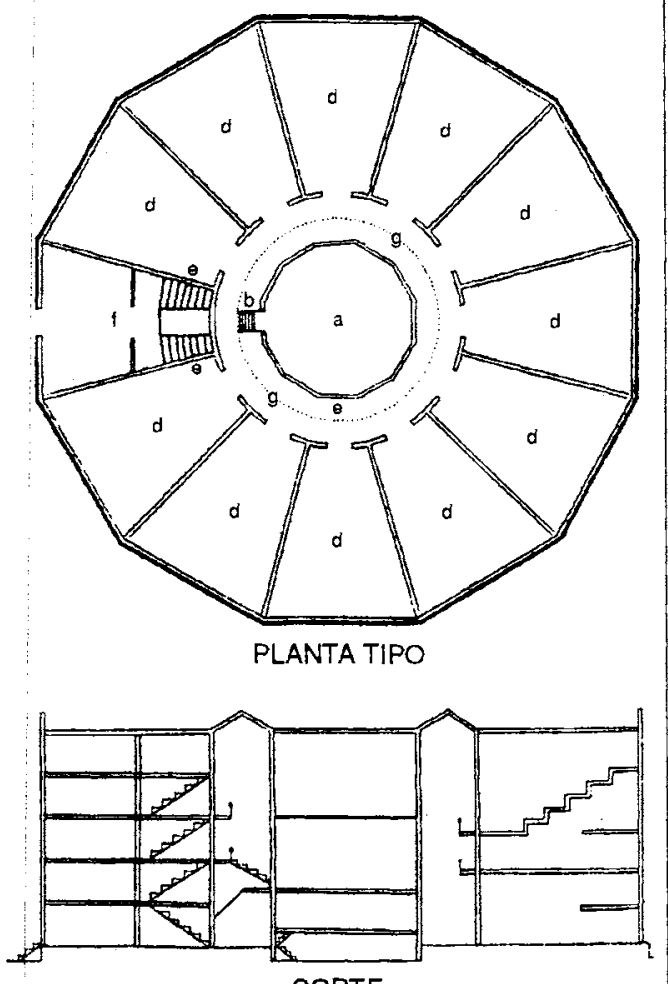

CORTE

a. Torre o inspección central.

b. Principio de la escalera de la torre.

c. Espacio anular entre la torre y el edificio principal.

d. Divisiones o celdas para los presos.

e. Escalera principal del edificio.

f. Entrada al mismo.

g. Galería.

modo que hiciese en ellos la impresión que se quiere producir, de asegurarse de sus acciones, de sus conexiones, y de todas las circunstancias de su vida, de manera que nada pudiera ignorarse, ni contrariar el efecto deseado, no se puede dudar que un instrumento de esta especie, sería un instrumento muy enérgico y muy útil que los gobiernos podrían aplicar a diferentes objetos de la mayor importancia.»

«La educación, por ejemplo...»

«Pero ¿cómo un hombre solo puede ser bastante para velar perfectamente sobre un gran número de individuos? ¿y aún cómo un gran número de individuos podría velar perfectamente sobre un hombre solo? ...»

«Sin dificultad pues se confesará que sería una idea tan útil como nueva la que diese a un hombre solo, un poder de vigilancia que hasta ahora ha superado las fuerzas reunidas en un gran número."

"Este es el principio que el señor Bentham cree haber resuelto con la aplicación constante de un principio muy sencillo, y entre los muchos establecimientos a que podría aplicarse este principio, las casas de reclusión han parecido merecer la primera atención...»

"Introducir una reforma completa de las prisiones, asegurarse de la buena conducta actual, y de la enmienda de los presos: fijar la salubridad. la limpieza, el orden y la industria (...) aumentar la seguridad disminuyendo el gasto en vez de hacerlo 
mayor, $y$ todo esto por una idea sencilla de arquitectura es el objeto de su obra».

(...) ¿ ¿Cómo se podrá establecer un nuevo orden de cosas? y establecido ¿Cómo se podrá tener la seguridad de que no degenerará?

"La inspección: este es el principio único para establecer el orden y para conservarlo; pero una inspección de un nuevo género, que obra más sobre la imaginación que sobre los sentidos, y que pone a centenares de hombres en la dependencia de uno solo, dando a este hombre solo, una especie de presencia universal en el recinto de su dominio» (18)

¿Cuáles son los aspectos revolucionarios en el tema del espacio arquitectónico que plantearía a su sociedad este singular proyecto?

El panóptico planteaba en forma consciente un conjunto de aspectos y preocupaciones que subyacían al conjunto del sistema productivo que se estaba configurando, directamente ligada su solución con la práctica arquitectónica. Veamos.

1. En lo relativo al programa aparece en el, la intencionalidad consciente de hacer que un dispositivo arquitectónico opere como determinante de ciertos efectos buscados y predeterminados, unidos a un tipo de construcción, que en su época, no era preocupación de ninguno.

Por otra parte, si bien aplicado a las prisiones, el dispositivo está planteado a partir de un conjunto de efectos sobre cualquier multiplicidad de individuos que sea necesario controlar, no importa la tarea que sobre ellos se imponga.

Es decir, lo que se plantea es la creación de un mecanismo que a través de cierto tipo de disposiciones espaciales se convierta en un aparato continuo de vigilancia.

Efectivamente, el programa no trata ya acerca de los efectos visuales y de espectáculo donde se ilustra la grandeza del poder del soberano, donde dicho poder deviene de la potencia del fasto.

Se trata ahora de otro tipo de mirada. No es el soberano que mira desde su altura o es mirado en su grandeza; es la creación de una nueva relación donde la luz enlazaba la subjetividad del individuo, con un nuevo tipo de poder, anónimo más que personificado, estratégico en lugar de amenazante.

Poder que se estaba configurando en una necesidad en las múltiples transformaciones económicas y políticas de esa sociedad.

2. Para ello, si nos detenemos en sus aspectos constructivos, particularmente vinculados con las prisiones, vemos que se ha operado una inversión.

La pesantez de los muros de piedra de los calabozos han sido reemplazados por la liviandad y transparencia del acero y del vidrio.

(18) Bentham. J. El Panóptico [1822] (1979. p. 33-34) 
Donde al individuo se lo ocultaba de la mirada de la sociedad; se lo depositaba lejos del contagio, privado de la luz, abandonado a la degradación del ocio, ahora se lo encierra sí, pero haciendo de la luz una trampa en su capacidad de evidenciar a través de las miradas, a la que ahora se lo expone.

Se trata de disponer la distribución espacial de los cuerpos en unidades. El objetivo es ver sin ser vistos. Quien padece sus efectos no sabe cuando es vigilado y cuando no.

Es decir, se hace operar la distribución del espacio buscando efectos que operen sobre la conducta de los individuos.

\section{¿Cómo? separando y mostrando}

Separando. «La multitud, masa, lugar de intercambio múltiple, individualidades que se funden, efecto colectivo, se anula en beneficio de una colección de individualidades separadas».

Mostrando. Con la creación de tantos pequeños teatros como celdas en que el actor está solo, perfectamente individualizado y perfectamente visible.

Distribución de cuerpos en el espacio.

Superficie de luces. Miradas.

Nada de rejas, cerrojos, cadenas, pesados muros de piedras.

Separaciones definidas y aberturas bien dispuestas.

Se disocia la pareja ver y ser visto.
Es aquí donde nos encontramos con un nuevo tipo de poder.

Visible e inverificable

Visible. En la existencia de la torre donde constantemente se supone ser mirado.

Inverificable. No se sabe si hay o no guardián.

Los individuos, así, se hallan en una situación de poder en la que ellos mismos son portadores.

El panóptico automatiza y desinvidualiza el poder.

No es ya el poder portado por un individuo, una jerarquía, una presencia visible. El poder se ha vuelto abstracto, impersonal, no tiene dueño ni figura que pueda ser visto e identificado.

Por eso está siempre presente.

Se ha sustituido al vigilante por $s u$ representación; es decir, se ha escamoteado el vigilante.

En el momento en que el individuo es atrapado en una situación simbólica, el poder se instala en la conciencia de cada uno atrapado por un dispositivo espacial.

No importa ya quien ejerce el poder. Se trata de una maquinaria que funciona sola. Maquinaria que además tiene vices democráticos, porque a la par, son vigilados los carceleros y todos quienes entran en contacto con aquellos que son atrapados.

«El que está sometido a un campo de visibilidad y lo sabe, reproduce por su cuenta las coacciones del poder; las hace jugar espontáneamente sobre sí mismo; inscribe en sí mismo 
la relación de poder (...) se convierte en principio de su propio sometimiento». (19)

Pero, volviendo a Bentham, lo importante del Panóptico es que no es sólo un modelo de prisión.

Es un modelo de manejo de multitudes, de ejercicio del poder, ya que puede, como señalamos, ser aplicado a hospitales, escuelas, fábricas. Un aparato que fabrica orden a través de la separación y el aislamiento de los cuerpos. Evita en las cárceles las malas influencias y los motines; en los hospitales los contagios; en las escuelas que los niños charlen y se distraigan; en la industria las riñas, los robos y distracciones.

La otra gran consecuencia es que fabrica saber, al constituirse en un gran mirador, un gran laboratorio donde todas las conductas pueden ser observadas; la imagen del científico del siglo XIX, que apartado del fenómeno lo puede catalogar, controlar, observar, introducir modificaciones, controlar su ritmo de trabajo, por ejemplo, o la evolución de una enfermedad, etc.

Opera también sobre la separación activa de los cuerpos lo que permite establecer agrupamientos en tipos, clases, subclases, etc. operando activamente sobre la clasificación que es uno de los paradigmas científicos más importantes del siglo XIX.

El hospital, por ejemplo, podrá expresar en su arquitectura la rígida estructura clasificatoria que operaría como base epistemologica de la medicina.

Veamos las ventajas que ofreció un dispositivo panóptico en un ejemplo arquitectónico como el hospital:

a. Rígido control de la masa de personas que permanecen y circulan: enfermos, visitantes, médicos, enfermeros, estudiantes.

b. Separación de enfermos por constituir diferentes clases sociales; diferentes sexos; edades; casos clínicos como materia de estudio, curación y control; diferencias por las características de los casos, contagio, gravidez, conflictos.

c. Transformación de la institución pública de caridad en instituciones cerradas -de secuestro- distintas de la sociedad, portadoras de un nuevo tipo de saber y productoras de diferencias.

Podemos pensar en el panóptico como un inmenso aparato funcionalizador a partir de la instauración de un nuevo orden.

El panoptismo, a través del panóptico como partido arquitectónico a veces, o a través de otros sutiles mecanismos, ganará el conjunto de la sociedad, porque las imposiciones del sistema harían necesarios el despliegue de formas de sujeción a través de un conjunto de estrategias destinadas, juntas o individualmente, a solucionar el conjunto de nuevos grandes

(19) Foucault, M. 1976 


\section{A MODO DE REFLEXION IV La sexualidad como dispositivo de poder}

La otra gran estrategia que desplegaría el proceso de dosmeticación de la fuerza de trabajo a lo largo de la consolidación del capitalismo, refiere a un proceso de moralización del conjunto de la sociedad, cuyo dispositivo dominante es la construcción de la sexualidad discursiva que caracteriza nuestra cultura occidental

En términos generales se trata, por un lado de organizar un dispositivo de familia proletaria que instaure socialmente un dispositivo de reproducción de la fuerza de trabajo al lado de la familia burguesa, cuyo objetivo es instaurar un dispositivo de alianzas a los efectos de los esquemas de acumulación y centralización del capital.

La sexualidad encerrada en la familia a través del deseo y la prohibición se estruturaría en la lucha contra las cuatro «psicopatías sexualess que inventaría el siglo XIX, definiendo cuatro sujetos paradigmáticos:

* La mujer histérica.

* El niño masturbador.

* La pareja malthusiana.

* El adulto perverso.

Producción de saber y verdad; de discursos de normalización, y de la necesidad de intervenir sobre las anormalidades y los anormales en beneficio de la sociedad, determinó que progresivamente, hubiera un grupo de individuos que asumieran socialmente esa cruzada, y en nombre de la ciencia y la sociedad intervinieran en el espacio, que el otro poder, el de la ley y los derechos declaraba soberano.*

Es decir, se empieza a justificar una clase de individuos con derecho y poder de ejercer la vigilancia. Grupo no necesariamente de las clases altas, personas que se atribuyen, sin ninguna delegación superior la tarea de mantener el orden y crear, para ellos mismos, nuevos instrumentos para asegurarlos. Pueden así controlar e intervenir al interior de las familias, verificar sus costumbres, su sexualidad, sus excesos. Comunidades religiosas, cuaqueros, metodistas, etc. Tenían la tarea de vigilar y asistir. Sociedades no religiosas de defensa de las costumbres, luego. Sociedades de autodefensa, paramilitares.

Un nuevo status moral del cuerpo redefinitía el conjunto de relaciones en el conjunto de la sociedad.

A los efectos de nuestros análisis, un catálogo de elementos determinantes en la construcción de los espacios: clausuras -el cuarto paterno destinado a la sexualidad ahora escondida, y el baño-, control -accesibilidad al cuarto de los niños- separaciones por sexos, por edades.

* Foucault, M. [1976 (2)]. problemas que plantea el sistema productivo que se consolida.

Veamos ahora, vinculado con el panoptismo, otros mecanismos que comienzan a hacerse presentes en la arquitectura.

\section{DISPOSITIVOS VIGILANTES EH ARQUITECTURA}

Esos dispositivos comprenden un catálogo de espacios, sistemas constructivos, pequeños partidos, inclusive programas manifiestos.

En el planteo de base de una escuela militar de la época, podemos encontrar una síntesis de un conjunto de dispositivos vigilantes que se integrarían progresivamente a la arquitectura, todos destinados al encauzamiento de las conductas individuales.

El programa de la escuela tenía como objetivos a resolver cuatro aspectos básicos:

* Educar cuerpos vigorosos: Imperativo de salud.

* Obtener oficiales competentes: Imperativo de calidad.

* Formar militares obedientes: Imperativos políticos.

* Prevenir libertinaje y homosexualidad: Imperativo de moralidad.

¿Cuáles son los dispositivos arquitectónicos que orientarían el conjunto de necesidades planteadas en el proyecto, con que los arquitectos de la época resolverían estos temas? 
- Mamparos estancos entre individuos separando las camas.

- Cada una de las células repartidas a lo largo de pasillos.

- Todos ellos con aberturas para una posible vigilancia continua.

- Ventanas acristaladas hacia los pasillos.

- Cada tanto el alojamiento de un individuo jerarquizado (oficial, maestro, celador, enfermero, guardia, etc.).

- En el comedor, estrado elevado para las mesas de inspectores.

- Letrinas con medias puertas para células sanitarias, estrictamente separadas unas de otras, de modo que no haya contacto entre iguales, pero que se puedan ver pies y cabeza.

Estos elementos que aún podemos ver en los baños de casi todos los lugares públicos, tiene por objetivo la construcción de máquinas de observar, donde se reticulan los comportamientos individuales, para formar, en torno de cada uno, un aparato de observación, de registro y de encauzamiento de la conducta.

Se trata, como señalamos, del panoptismo incorporado a la vida cotidiana.

Nuevas disposiciones que se incorporarían a la vivienda.

Hasta el siglo XVII lo dominante era la uniformidad de espacios únicos donde convivían la familia (en el caso de los campesinos, familia eran todos los que vivían bajo el mismo techo, no importa el origen), donde varias generaciones compartían el calor de los animales, en las viviendas pudientes en una planta sobre el establo, en los más pobres todos juntos, patrones y sirvientes.

La casa empezaría separando los dormitorios, donde fue preciso inventar la chimenea a los efectos de reemplazar el calor centralizado, marcando entonces las distancias entre clases, generaciones, sexos, definiendo pequeños encierros, controles y prohibiciones que determinarán los partidos de la vivienda hasta nuestros días.

\section{A MODO DE URA PRIMERA SIITESIS}

Cuatro dispositivos históricos y sus correlatos con situaciones espaciales:

- La ciudad apestada la idealidad del funcionamiento de la ciudad como no-ciudad a través de la represión reglamentada.

- El campamento militar la disposición espacial orientada a la vigilancia jerarquizada.

- El apestado y los mecanismos de secuestro legitimando los dispositivos de poder-saber que genera el panoptismo y los disemina socialmente.

- El panoptismo La máquina de vigilar, mirada, vigilancia internalizada, la corrección.

Más de un siglo transcurre entre los reglamentos de la ciudad apestada y el panóptico donde se puede observar como se perfila el paso de uno a 
otro, todo un conjunto de cambios en la concepción del manejo del poder y sus correlatos espaciales.

En la ciudad apestada, contra el mal extraordinario, el poder actúa con toda su energía. Se hace presente y visible donde se pone en juego la vida y la muerte. Compartimenta, inmoviliza y reticula.

Funda dos imágenes complementarias: La contra ciudad en la liquidación de la mezcla, lo azaroso, el intercambio, el movimiento; a la par que la sociedad perfecta: estratificada, cuadriculada y obediente.

La ciudad apestada es el campamento militar trasladado al conjunto de la sociedad, el sueño del poder que se muestra.

El panóptico en cambio, es el modelo general, el modelo ideal del control de todos por todos, el modelo cuasi democrático.

La transparencia de la sociedad ante la oscuridad del poder soberano.

Ya no hay terceros en juego (nobleza, jerarquías, etc.).

El poder funciona como una maquinaria.

La mirada del control está inscripta en cada uno.

El poder pierde su visibilidad y parece desparramarse en todos los otros. La sociedad panoptizada es la utopía que la burguesía realiza.

Así, mientras la ciudad apestada ofrecía un modelo ideal perfecto pero violento; el panóptico ofrece el otro

(20) Marx, Carlos. [1867] modelo real continuo, invisible, pacífico, permanente.

Los dispositivos de secuestro construirán las formas legítimas de ejercicio del poder discriminatorio, a través de su configuración en instituciones necesarias al «buen funcionamiento» $\mathrm{y}$ «orden» de la sociedad.

Fundarán las formas científicas de discriminación, permanencia, encierro, que posibilitarán los dispositivos de control del tiempo de los individuos, en la nueva sociedad, donde el trabajo se está configurando como tiempo de trabajo.

\section{EL SISTEMA CAPITALISTA Y SUS ESPACIOS}

El advenimiento del proceso de producción capitalista y su explosiva revolución industrial tuvieron como punto de partida un proceso de acumulación primitiva, que a la par de hacer posible la concentración de inmensos volúmenes de capital en manos privadas, produce la expropiación del productor directo de sus medios de producción, liberando inmensas cantidades de individuos sólo poseedores de su fuerza de trabajo. (20)

Es decir, a través de diversas formas de violencia, produce una inmensa concentración de cuerpos disponibles para la demanda de la industria que producirán una gran expansión en las ciudades, pronta a vender su fuerza de trabajo.

Este período crucial en la historia 
de la humanidad, se registra en la historia de la arquitectura a través de una serie de facetas: el explosivo crecimiento de las ciudades con la aparición de los barrios obreros, y sus consecuencias: hacinamiento y promiscuidad; las utopías urbanas; nuevas funciones; nuevos materiales de construcción, etc.

Los espacios, juegan así un papel subordinado, son consecuencia de procesos sociales «naturales», normales al desarrollo industrial y a la acumulación capitalista.

El funcionalismo va a aparecer como la propuesta de la época industrial y del avance de la ciencia ligado al diseño.

Una mejor aproximación crítica formularía el ordenamiento de las ciudades a partir de la apropiación privada del espacio por las clases dominantes, las funciones urbanas vinculadas con los procesos productivos y finalmente los modelos de economía urbana y regional ligados a los costos de producción, el precio de la tierra y la especulación de la industria de producción de viviendas.

Haussman, el urbanista de la ciudad ocupada por el ejercito lanzado contra el pueblo, mostrará una nueva variable al diseño, ya que sus calles no sirven, sólo para la circulación de hombres y mercancías como lo venían demostrando las barricadas, instrumento de las insurrecciones populares.

La razón teórica del nuevo urbanismo de avenidas y bulevares estaba vinculada con el emplazamiento y al- cance de los cañones apuntando al pueblo parisino.

Los espacios interiores pasarían de la monumentalidad de los templos o del amontonamiento anárquico de hombres trabajando a la racionalidad de las economías de las funciones. (21)

La máquina será la gran metáfora de la época vinculada con la conciencia aparente que dominaría la autorreflexión del período.

Ahora bien, si retomamos como punto de partida el fenómeno de grandes masas de individuos «liberados» de sus lazos feudales, comunales, convertidos en fuerza de trabajo, que adquieren en esa sociedad el anonimato de ser individuos diferenciados unos de otros, enfrentados unos con otros en todos los ámbitos -particularmente en el mercado de trabajo- y la categorización colectiva de ser población, constituyendo un nuevo orden de problemas.

El sinnúmero de nuevos problemas «hechos de población» serían las preocupaciones de la burguesía naciente que empieza a tomar conciencia de su época.

El imperativo de fuerza de trabajo saludable plantea situaciones vinculadas con la salubridad, la higiene social que tienen directa relación con lugares de inserción, entorno, localización.

No serán los arquitectos de la época sino los médicos los que se configurarían en especialistas del es-

(21) Una descripción descarnada acerca de estos temas urbanos, la realizaría Engels en «La Situación de la Clase Obrera en Inglaterra». 
pacio, a partir, precisamente de la acumulación de cuerpos en los ámbitos urbanos.

Cuatro problemas espaciales adscriptos a temas médicos-espaciales de esa época:

1. Problemas de los emplazamientos: tema de los climas regionales, naturaleza de los suelos, humedad y sequedades del ambiente, etc.; problemas climáticos y estacionales.

2. Problemas de la coexistencia. El hacinamiento, cuerpos humanos acumulados sin discriminación alguna, densidad y proximidad; hombres y animales; cuerpos vivos y cuerpos muertos; hombres y cosas (aguas servidas, alcantarillados, ventilación, excretas).

3. Problemas de la residencia. Hábitat, conformaciones urbanas.

4. Problemas de desplazamientos. Propagación de enfermedades a través de migraciones. (22)

Las respuestas a este tipo de problemas no se plasmaban en su totalidad en propuestas espaciales, no obstante conformaron una nutrida normativa urbana que llegó hasta nuestros días.

Otro orden de problemas generarían los hechos de población vinculados con los inicios del capitalismo.

Una pregunta no formulada en el desarrollo del capitalismo naciente

(22) Cfr. Foucault, M. (1978) Preguntas a Michell Foucault sobre la Geografía. p. 111 También en Foucault, M. (1990) Historia de la medicalización. p. 121 fue: por qué esa masa de población que venía a las ciudades desalojados del campo, asumían convertirse en obreros, ser encerrados doce o más horas en un local y obligados a trabajar para otro, sin conflictos permanentes?

¿Por qué no dedicarse al bandidaje $\mathrm{o}$ al robo? $¿ \mathrm{O}$ a otra forma de supervivencia? ¿Cómo se pudo hacer que este hombre asumiera pasar la mayor parte de su vida consciente haciendo el mismo movimiento como apéndice de la máquina?

El poder centralizado, soberano, aleccionador era sólo compatible con los regímenes productivos en los que se asentaba, pero totalmente antieconómico para las nuevas formas que construía el capitalismo.

Vagabundos, villanos, bandoleros producidos por los regímenes agrarios en descomposición sólo podían ser controlados por aparatos represivos caros e ineficaces. Enrique VIII, aparte de haber sobrevivido a seis esposas, hizo colgar alrededor de setenta mil individuos por vagancia, amputar miembros, marcarlos, cortar orejas, etc.

Este régimen es totalmente incompatible para un sistema donde cada uno es fuerza de trabajo necesaria a un mercado en expansión.

La respuesta empezaría a esbozarse en la sociedad panoptizada y en los dispositivos de secuestros a partir del nuevo tipo de poder, que empieza a inscribirse en la relación entre los 
iguales y a internalizarse en formas de vigilancia generalizada, del control de todos por todos.

La otra forma que la sociedad irá construyendo, silenciosamente, minuciosamente y en forma permanente y silenciosa al lado de los grandes discursos de la democracia y soberanía son las disciplinas.

Las disciplinas suponen una tecnología, un bagaje de técnicas orientadas a determinar la docilidad de los cuerpos. Ellos son:

\section{El control del tiempo}

El control del tiempo, está vinculado con la construcción del individuo como fuerza de trabajo, de la transformación del tiempo a que estaba ritmada la sociedad a partir de los ciclos agrícolas, estacionales, natural, al tiempo de la industria repetitivo, permanente, constante, partiría de tres procedimientos:

a. Establecer ritmos. Ritmos de marcha, ritmos de trabajo, es decir que las tareas impliquen actividades que puedan ser divididas en múltiples unidades.

b. Obligar al individuo a una ocupación determinada, permanente, donde se pueda mensurar el procesos de trabajo. Para

c. Regular los ritmos de repetición.

\section{El control de la actividad}

Aquí se trata de operar sobre la configuración misma del cuerpo, a

\section{A MODO DE REFLEXION V. Las disciplinas}

¿Que son las disciplinas? ¿A qué se llama disciplina? La disciplina conforma una forma de dominación cuya característica es el ejercicio permanente e invisible del control de los individuos.

«Implica una coerción ininterrumpida, constante, que vela sobre los procesos de la actividad más que sobre su resultado y se ejerce según una codificación que retícula la mayor aproximación del tiempo, el espacio y los movimientos.

«Estos métodos que permiten el control minucioso de las operaciones del cuerpo, que garantizan la sujeción constante de sus fuerzas y les imponen una relación de docilidad-utilidad, es lo que pude llamar «las disciplinas».*

Esta dominación, distinta de la esclavitud -ya que el hombre es virtualmente dueño de su propio cuerpo-, de la domesticidad, ya que el control no es un ejercicio permanente; del vasallaje, ya que no hay una relación con el producto del trabaja; o con cualquier otra forma de dominio antes ejercida.

Se trata de una forma de sujeción funcional a la nueva imagen del «hombre libre», del hombre urbano que culminará con el ciudadano de las formas republicanas de gobierno.

* Foucault M. [1976]. p. 141 esos efectos se debe establecer, modelar, definir:

a. La correlación del cuerpo y el gesto. Se trata de crear una normalidad tanto en las situaciones de movimiento como de reposo, permanencia, donde el cuerpo del individuo adopte como natural, propias, posiciones y movimientos impuestos, estudiados, orientados a un fin determinado.

Las posiciones militares son el mejor ejemplo, firmes, descanso, la marcha en formación; también lo 
son la posición de atención, sentados largo tiempo en los institutos de enseñanza, o la serie de coordinaciones que supone la posición de escribir.

b. La articulación del cuerpo y del objeto.

Aquí de nuevo la imagen del soldado y el manejo del arma como formando parte de su cuerpo; el hombre instrumento.

El perfeccionamiento del gesto entre el hombre y la máquina o de la herramienta. Se perfeccionan los gestos dictados por las máquinas donde toda su corporeidad se reduce al movimiento de determinados miembros, medidos, repetitivos, etc. El hombre reduce su corporeidad al movimiento de brazos, o de manos en concordancia con el objeto que teóricamente maneja.

c. La utilización exhaustiva de sus energías.

Ningún movimiento, pensamiento o gesto que lo aparte de la tarea que realiza. No hay espacios ni tiempos de actividades inútiles $u$ orientadas con otro fin.

Con todos estos elementos y la operatividad de determinados aspectos espaciales se construyó al cuerpo como una máquina.

Al cuerpo se lo modela, encierra, registra, presiona, castiga, controla a los efectos de obtener una nueva forma de dominación, ahora integrada, esencial al individuo. Así:
1. El cuerpo ahora es un elemento móvil, reemplazable, que ocupa un lugar, un intervalo, una regularidad, un orden. El soldado es ahora un fragmento de espacio móvil, antes que una valentía o un honor. La tarea, el lugar, la función, definen la identidad del cuerpo en ese nuevo orden.

2. Para ello se elabora sobre él una composición de fuerzas y del tiempo, donde cada serie, cada conjunto, cada grupo puede rendir al máximo a partir de movimientos disciplinados.

3. Se elaboró un nuevo sistema de ordenes. La orden se inscribe en la tarea. No debe ser explicada, a veces ni formulada. La orden se internaliza en el cuerpo, se inscribe a veces en un objeto y debe ser cumplida en el espacio y tiempo de la ocupación.

La disciplina, así, «"Encausa” las multitudes móviles, confusas, inútiles de cuerpos y de fuerzas de una multiplicidad de elementos individuales pequeñas células separadas, autonomías orgánicas, identidades y continuidades genéticas, segmentos combinatorios. La disciplina "fabrica" individuos; es la técnica específica de un poder que se da a los individuos a la vez como objetos y como instrumentos de su propio ejercicios». (23)

¿Cuál es el papel de los espacios en la determinación de las prácticas del poder disciplinario? 
La determinación de diversos tipos de espacios son constituyentes y resultan instrumentos para la práctica del poder disciplinario.

¿De qué tipo de espacios estamos hablando?

\section{El espacio de clausura}

Se trata de destruir las heterogeneidades, determinando los espacios donde se redefina lo homogéneo.

El cuartel; el asentamiento del ejército, por ejemplo. Qué es el ejército sino una masa indisciplinada de campesinos, vagabundos, saqueadores y violentos construidos como soldados? Con la clausura se evitan deserciones, mezclas con el exterior, control de los gastos.

El modelo de base es el convento. Las órdenes religiosas conservan su identidad a partir de la clausura. No hay circulación aleatoria entre el interior homogéneo y el exterior con sus heterogeneidades. Hay un control estricto en la circulación de hombres y cosas. Los espacios tienen jerarquías de accesos a través de diversos niveles de prohibición.

Sobre ambos modelos se orientan la creación de manufacturas y colegios a fines del siglo XVIII. Las manufacturas reunidas y a posteriori fábricas se inician sobre modelos de reclusión -particularmente de mujeres y niños- pero como todas formas de violencia directa (el control del encierro) serían reemplazadas por formas más sofisticadas de disciplinas.
No obstante, asumamos el papel conformador de situaciones disciplinarias de los espacios de clausura. Ya que en mayor o menor medida, todas las instituciones que nos «disciplinan»-establecimientos educacionales, hospitalarios, judiciales, carcelarios o laborales- funcionan con situaciones espaciales de clausura.

\section{Organización de espacios analíticos}

\section{Hablamos de localizaciones ele- mentales y división en zonas}

i. A cada individuo su lugar y a cada emplazamiento un individuo: el espacio modulado.

ii. Hacer analíticos los grupos: descomponer sus implantaciones colectivas; analizar las pluralidades confusas, masivas, huidizas.

iii. Dividir en tantas parcelas como cuerpos o elementos hay que repartir. Hacer posible así, establecer presencias y ausencias. Dónde y cómo encontrar individuos y cosas anulando los efectos de distribuciones indecisas.

iv. Instaurar las comunicaciones precisas y necesarias. Eliminar las que no lo son.

Con todos estos elementos el espacio adquiere características mecánicas. Permite controlar los individuos; quiénes y dónde están; evidenciar las circulaciones difusas, las concentraciones peligrosas o inutilizables. 
Permite vigilar las conductas y méritos de cada cual, cualificar o sancionar.

Sobre este modelo espacial se instaura el modelo de aprendizaje. La formación de cuadros con filas y columnas; el alumno localizado, controlado, calificado.

El trabajador en su lugar, controlado en su presencia y producción.

De nuevo la génesis, la imagen histórica es la arquitectura del convento con su dormitorio como celdas.

Este espacio celular puede estar compuesto de compartimientos materiales (celda) o compartimientos ideales (el banco o la formación).

\section{Los emplazamientos funcionales}

Espacios que la arquitectura destinaba a un sinnúmero de usos, comenzarán a ser objetos de analiticidad, a los efectos de la obtención de máximas utilidades. No se fijan los lugares sólo para evitar confusiones, localizar, vigilar o romper comunicaciones sino también de extraer utilidad máxima en la distribución.

Tres modelos de organización funcional se plasmarán en el mismo período a partir de la máxima utilidad de los espacios:

El puerto marítimo donde la gran combinatoria de hombres y cosas en perpetuo movimiento, cruce, traslado, intercambio, determinaba altos niveles de robos, pérdidas, confusiones, descontroles, tráficos ilegales de mercancías y de cuerpos, deserciones, etc.
El hospital, donde los avances de la medicina redefinían y taxonomizaban enfermedades y enfermos, cruce de cuerpos sanos con un largo repertorio de categorías: médicos, enfermeras, auxiliares visitantes; peligrosidades por contagios, circulación de cosas: medicamentos, alimentos, ropas; lugares de depósitos, etc.

Nuevamente la fábrica, donde el acelerado proceso de división del trabajo determina una descomposición individualizante de la fuerza de trabajo, a la par que la concentración de masas es preciso ordenar en función de las determinantes de la producción, a la par que controlar, vigilar los ritmos, proveer de insumos, movilizar las manufacturas. La creación de puestos de trabajo supone la analiticidad fundada en el rendimiento determinado por la armonía entre masa e individuo, producto de la división del trabajo.

Este proceso de utilización del espacio es una larga construcción histórica en cuyo resultado convergen dispositivos de poder y saber largamente elaborados e instaurados -no sin batallas- como mecanismos de normalidad social.

La creación del espacio útil es concomitante con la creación del individuo, con la individualización del sujeto y su analiticidad no es privativa de los profesionales de la construcción, sino de distintos profesionales situados estratégicamente en las situaciones críticas que las nuevas instancias productivas y/o sociales condicionaron a resolver. 


\section{Elementos Intercamblables y definición de rango}

Los espacios disciplinarios no se definen por situaciones coaguladas de dominación o de residencia, esos espacios no corresponden a situaciones de privilegio. No pertenecen. No tienen dueño.

Cada espacio se define por tres elementos: el lugar en una clasificación, en el punto donde se cruzan una fila y una columna, y el intervalo que se establece en una serie. El espacio que debe recorrerse entre uno y el otro elemento; el rango.

Este espacio de distribución predetermina el lugar, pero no lo que ese lugar va a contener. En ese sentido, los elementos son intercambiables.

Nadie es dueño de una cátedra o de un banco o tablero en la facultad, o de la cama de un hospital o del lugar en la línea de producción; no importa quien es el individuo soldado que ocupa un determinado lugar en una fila o determinada cama en una cuadra. Está situado y determinado su rango

Organización en clases por complejidad, en filas y columnas en la distribución de la clase por algún tipo de orden, en la educación méritos y dificultades. La definición de espacios seriales convierte la escuela en máquinas de aprender y al ejercito en máquinas de guerra. Cualquier individuo es un escolar o un soldado introducido en el aparato disciplinario.

«Al organizar las 'celdas', los 'lugares' y los 'rangos', fabrican las dis- ciplinas espacios complejos: arquitectónicos, funcionales y jerárquicos a la vez:

Son los espacios que establecen la fijación y permiten la circulación; establecen segmentos individuales $e$ instauran relaciones operatorias; marcan lugares e indican valores; garantizan la obediencia de los individuos pero también una mejor economía del tiempo y de los gestos. Son espacios mixtos: reales, ya que rigen la disposición de pabellones, de salas, de mobiliärios, pero ideales, ya que se proyectan sobre la ordenación de las características, de las estimaciones, de las jerarquías»

El objetivo: la formación de «cuadros vivos que transforman las multitudes confusas, inútiles, peligrosas en multitudes ordenadas»

La táctica: el ordenamiento espacial de hombres y cosas.

La taxonomía -el espacio de ordenación de los seres naturales en una estrategia de conocimiento- es transformada en dispositivo disciplinario en el orden de los cuerpos.

Tiene como función caracterizar reducir singularidades individuales- $y$ constituir clases, para así excluir consideraciones de número.

Todos estos elementos que constituyen una «lógica de los espacios» y son en última instancia un catálogo de posibilidades combinatorias con que todos los días operamos los diseñadores.

Son una larga construcción a los 
efectos de lograr efectos permanentes y duraderos del dominio de ciertas fracciones en la sociedad en forma de poder saber, en la que somos correa de transmisión.

Un objeto tan obvio como la vivienda -donde creemos las sabemos todas, hemos visto, está atravesada por espacializaciones de los dispositivos de sexualidad con que se construyó el discurso de la moral.

Podemos también, con ojear su historia en los albores del capitalismo, ver como fueron aplicados los dispositivos de individualización, estructuras celulares, particiones, aislamientos, a través del ejercicio consecuente de los reformadores y filántropos y moralistas ingleses.

Las descripciones de los barrios de viviendas obreras, tenían el común denominador de constituir intrincadas mallas de accesos, pasajes, bifurcaciones, que hacían casi imposible la identificación de los espacios, sino para los que allí habitaban, y dificultosa la orientación para cobradores, agentes patronales, policías, etc. Como consecuencia de eso, no existían las condiciones que hoy suponemos «morales» en lo relativo al contacto entre personas de diversos

(24) No puede pensarse ya una historia de la arquitectura sin una historia de la vivienda. $Y$ no podemos, en esta empresa, prescindir de una de las investigaciones colectivas más importantes editadas en las últimas décadas. Se trata de: Ariès P., Duby, G. Historia de la vida privada., donde en cada una de las épocas la vivienda es una presencia imprescindible. Importa destacar los trabajos de la Doctorá Michelle Perrot referidos a los siglos XVII y XIX. sexos, edades, etc. Mucho menos las condiciones de higiene que estaba construyendo la burguesía a través del imperativo de cuerpo sano para preservar su descendencia y soldar sus alianzas.

Las campañas de salubridad y moralidad, -y como consecuencia de control social- tuvieron como uno de los principales blancos, la transformación del espacio de la vivienda.

El principal dispositivo fue el de las particiones. Redefinición de la familia: individualización de la misma y determinación de los espacios concomitantes.

Redefinición de los roles de la familia;

1. económicos: definiendo el destino de cada uno como fuerza de trabajo;

2. moral: organizando una férrea partición, separación y control a través de la construcción de una sexualidad discursiva socializada y controlable;

3. social: eliminando la convivencia entre personas de distinto origen y clases (allegados, servidumbre, parientes).

Cada casa un lugar en una calle y un número, en su interior la funcionalidad de las particiones múltiples.

Esa es una historia de la vivienda en los últimos siglos. La construcción de una vida privada como atributo del individuo, que la tenemos inscripta como eterna y universal. (24) 


\section{ACERGA DEL PAPEL DEL DISEIIADOR Y SUS ESPACIOS}

Si tenemos el valor de asumir esta nueva mirada del individuo en nuestras sociedades - donde el «hombre» idealizado por el humanismo es, dominantemente un cuerpo disciplinado y vigilado, sobre el que operan dispositivos múltiples de estrategias $\sin$ sujetos que definen conductas, sujeciones, determinan pautas, en fin, modelan su vida- necesariamente nuestra mirada de los espacios que crea y su historia debe sufrir modificaciones.

Por otra parte, si asumimos el papel activo de la conformación de los espacios en la creación, permanencia, mantenimiento y desarrollo de los dispositivos disciplinarios y vigilantes la relación entre los espacios con los que operamos y la sociedad empieza a adquirir connotaciones materiales.

Una puntualización acerca de nuestra práctica que derivaría de lo visto nos indicaría que:

\section{Absolutamente ningún espacio es} neutro. Todo aquel que supone que el acto de proyectar no tiene consecuencias, comete un error o actúa sin conciencia.

Vivimos proponiendo espacios disciplinarios creadores permanentemente de formas asimétricas de conductas, las que siempre dan po- der a los poderosos.

Vivimos pensando en categorías de encierro y/o secuestro para todo espacio que implique algún tipo de especialización.

No podemos sustraernos a las formas panópticas de pensamiento de los espacios colectivos.

2. No quiere decir esto que existan «espacios para la liberación» o que haya atajos que nos permitan salir de los dispositivos disciplinarios o vigilantes. Las premisas de funcionamiento de esta sociedad los suponen y los reproducen.

3. No obstante, el primer paso en todo proceso de posible transformación en que podamos inscribirnos en tanto profesionales del diseño, debe pasar por la conciencia y la reflexión del papel que opera nuestra tarea en la conformación de la sociedad en que nos ha tocado vivir.

4. De allí el papel de nuevas utopías, o la renovación de las utopías, en las que no se reproduzcan las formas que hicieron posible la disposición actual de la sociedad, su distribución desigual de saber, poder, cultura, definida por la arbitrariedad del poder que se potencia.

5. Se trata en principio de empezar a ver, a partir de nuevos observables, la realidad que nos rodea, particularmente, en el campo que nos toca participar activamente

6. Se trata, finalmente, de repensar los valores y reorientar la crítica. 


\section{BIBLIOGRAFIA}

Ariès P., Duby, G. Historia de la vida privada. Buenos Aires. Taurus. 1990.

Bentham, J. Tratados de legislación civil y penal... [1822]. Publicado bajo el nombre de El Panóptico. Madrid. La Piqueta. 1979.

Borges, Jorge Luis. Obras Completas. Buenos Aires. Emecé Editores. 1974.

Elías, Norbert. La sociedad de los individuos; ensayos; Ediciones Península, Barcelona; 1990.

Engels, F. La situación de la clase obrera en Inglaterra. Buenos Aires. Editorial Esencias.

Foucault, M. Vigilar y Castigar. México. Siglo XXI Editor. 1976.

Foucault, M. La verdad y las Formas Juridicas. Barcelona. Gedisa. 1980.

Foucault, M. Historia de la sexualidad. I. La voluntad de saber. México. Siglo XXI Editores S.A. 1980

Foucault, M. Microfísica del Poder. Madrid. La Piqueta. 1981.

Foucault, M. Espacios de Poder. Madrid. La Piqueta. 1981.

Fourquet, F. Murard, L. Les équipements du puvoir. París. Recherches/13. 1973.

Marx, C. El Capital. Crítica de la economía política. [1867]. Siglo veintiuno editores. México. 1975.

Togneri, Jorge. Polémica en la arquitectura. Buenos Aires. Espacio Editora. 1984. 